QUADERNS DE FILOSOFIA VOL. II NÚM. I (2OI 5): 25-38

ISSN: 234I-I4I 4 DOI: IO.7203/QFIA.2.I.45I 4

Maria Cristina Fornari

Università del Salento

\title{
Talis hominibus fuit oratio qualis vita. Nietzsche y la narración de sí
}

Traducción de Nerea Miravet y Héctor Vizcaíno*

Recibido: 29/12/14. Aceptado: 7/2/15

Resumen: Ecce homo es desde luego una autobiografía sui generis. Alejada de los modelos clásicos de la autonarración, no solo narra una vida que coincide esencialmente con las etapas de la producción literaria, sino que sobre todo tiene como protagonista a un "yo" que ya no coincide con el sujeto de la tradición. Se plantea la hipótesis de que Nietzsche esté a la búsqueda de un nuevo modelo de subjetividad: no una adquisición estable, sino una construcción móvil, una tensión dinámica, que se descubre en el momento mismo de su constituirse, de su "convertirse en lo que es", esto es, en la respuesta consciente al propio, fatal, destino.

Abstract: Ecce homo certainly is an unconventional autobiography. Both its structure and its contents are in fact quite different from that traditionally adopted. First, in Ecce Homo life and literary production basically coincide; second, in that book Nietzsche deals with an "I" which is not the traditional "subject" of Western philosophy. In this paper I shall argue that in Ecce homo Nietzsche tries to develop a new kind of subjectivity. In particular, Nietzsche rejects the idea of an unchanging,

* Los traductores dan las gracias a sendas becas de carácter pre-doctoral del Subprograma "Atracció de talent" de la Universitat de València y en el marco del proyecto de investigación "Hacia una Historia Conceptual comprehensiva: giros filosóficos y culturales" (FFI2011-24473) del Ministerio de Economía y Competitividad. Mientras no se indique lo contrario, la traducción al español de las citas es nuestra. 
absolute, substance subject, and sees it as a mobile construction, something that can be described only insofar as it "becomes what it is", that is, as it consciously reacts to its unavoidable destiny.

Palabras clave: autobiografía, subjetividad, conocimiento de sí.

Keywords: autobiography, subjectivity, self-knowledge.

\author{
A part of Fate is the freedom of man \\ Ralph Waldo Emerson, Fate
}

Wenn alle Dinge ein fatum sind, so bin ich auch allen Dingen fatum Friedrich NieTZsche, FP 29[13] $1884^{1}$

I. Un precoz impulso autobiográfico se manifiesta en Nietzsche cuando este apenas tiene doce años. La primera anotación de su diario - apenas dos hojas, las otras extraviadas o quemadas, que cuentan las Navidades de Naumburgo del año 1856 y los gratificantes regalos - se abre con la ingenua voluntad de

\footnotetext{
${ }^{1}$ A lo largo del texto se utilizan las siguientes siglas: BN: Biblioteca personal de Nietzsche; EC: Ecce homo [Trad. cast. Ecce homo. Cómo se llega a ser lo que se es, introducción, traducción y notas de Andrés Sánchez Pascual, Madrid: Alianza Editorial, 2005]; GD: Crepúsculo de los idolos [Trad. cast. Crepúsculo de los ídolos o Cómo se filosofa con el martillo, introducción, traducción y notas de Andrés Sánchez Pascual, Madrid: Alianza Editorial, 2002]; GM: Genealogía de la moral [Trad. cast. La genealogía de la moral. Un escrito polémico, introducción, traducción y notas de Andrés Sánchez Pascual, Madrid: Alianza Editorial, 2008]; HL: De la utilidad y los inconvenientes de la historia para la vida. Segunda consideración intempestiva; [Trad. cast. De la utilidad y los inconvenientes de la historia para la vida, en Nietzsche, F., Obras Completas. Volumen I: Escritos de juventud, traducción, introducción y notas de Joan B. Llinares, Diego Sánchez Meca y Luis E. de Santiago Guervós, Madrid: Tecnos, 20 I I , 695-748]; FP: Fragmentos póstumos [Trad. cast. Fragmentos póstumos, vol. I (1864-1874), traducción, introducción y notas de Luis E. de Santiago Guervós, Madrid: Tecnos, 2007; vol. II (1875-1882), traducción, introducción y notas de Manuel Barrios y Jaime Aspiunza, Madrid: Tecnos, 2008; vol. III (1882-1885), traducción, introducción y notas de Diego Sánchez Meca y Jesús Conill, Madrid: Tecnos, 20ro; vol. IV (1885-1889), traducción, introducción y notas de Juan Luis Vermal y Joan B. Llinares, Madrid: Tecnos, 2006]; FW: La gaya ciencia [Trad. cast. La gaya ciencia, Traducción y notas de Juan Luis Vermal, en Nietzsche, F., Obras Completas. Volumen III: Obras de Madurez I, Madrid: Tecnos, 2014, 703-905]; MA: Humano, demasiado humano [Trad. cast. Humano, demasiado humano. Volumen I y II, Traducción y notas de Marco Parmeggiani, en Nietzsche, F., Obras Completas. Volumen III: Obras de Madurez I, Madrid, op. cit., 20 I4, 67-466]; WS: El caminante y su sombra [Trad. cast. "El caminante y su sombra", en Humano, demasiado humano. Volumen II, traducción y notas de Marco Parmeggiani, en Nietzsche, F., Obras Completas. Volumen III: Obras de Madurez I, Madrid: Tecnos, 2014, 371-466]. [N. de los T.]
} 
mantener el recuerdo de esos instantes placenteros. ${ }^{2}$ Le siguen otros, en varias versiones: la descripción de su aldea natal; la primera niñez, que "discurrió apacible y serena, y me arrulló suavemente igual que un dulce sueño"; la muerte del padre; los amigos; las lecturas; las pasiones. Lebenserinnungen, recuerdos de vida, que Nietzsche trata de alargar de manera sistemática, ya con una cierta, feliz, libertad expresiva.

El jovencísimo Nietzsche no tiene, ciertamente, una intención consciente que vaya más allá del registro de los hechos que ya considera destacados para su existencia - no tendrá en mente un Bildungsroman o el Zweckroman de la literatura edificante y religiosa - pero desde luego ojea sus modelos, antes que ningún otro Goethe, cuyo Dichtung und Wahrheit representaba entonces una referencia obligada y de la que serían testigos "una cierta ambición literaria atestiguada por el título" " y la distinción entre poesía y verdad, encausada explícitamente. "Es muy bello volver a evocar más tarde a nuestro espíritu los primeros ańos de nuestra vida, y reconocer así el desarrollo de nuestra alma. He escrito aquí fielmente la verdad, sin invenciones ni adornos poéticos", 5 escribe Nietzsche, y el pensamiento se dirige también a Montaigne, que dedica sus Ensayos a parientes y amigos "para que después de perderme [...] puedan encontrar en sus páginas algunos rasgos de mi temperamento y humor $[\ldots]$

2 "Finalmente está tomada la decisión de escribir un diario en el que confiar a la memoria todo aquello que de triste o dichoso conmueva a mi corazón, de tal manera que, con el paso de los ańos, pueda volver a la vida y a la actividad de esta época y, sobre todo, recordarme a mí mismo" (Nietzsche, F. i998, Scritti giovanili 1856-1864, Campioni, G., Carpitella, M. (eds.), Milán: Adelphi, 3).

${ }^{3}$ Nietzsche, F. 20 I I, "Esbozos autobiográficos (1858-1869)", en Obras Completas. Volumen I: Escritos de juventud, traducción, introducción y notas de Joan B. Llinares, Diego Sánchez Meca y Luis E. de Santiago Guervós, Madrid: Tecnos, 5[1], 86.

${ }^{4}$ Así Campioni G., Carpitella M., op. cit., 493. Siendo para Goethe "el cometido principal de la biografía: representar al hombre en las circunstancias de su época y mostrar en qué medida se resiste a ellas, en qué medida le favorecen, cómo a partir de ellas se ha formado una visión del mundo y de los hombres y cómo, si se trata de un artista, poeta o escritor, ha proyectado esta visión al exterior" (Goethe, J. W. 2010, Poesía y verdad, traducción, introducción y notas de Rosa Sala, Barcelona: Alba, 21), también para Nietzsche "Echar una ojeada al tiempo pasado de la vida y enlazar pensamientos con los acontecimientos más importantes de ella, es algo que no puede ni debe carecer de interés para alguien que dé importancia a su propio desarrollo moral y espiritual. Pues, si bien las semillas de las predisposiciones individuales y morales ya se encuentran ocultas en nosotros, y la base del carácter de cada hombre es, por así decirlo, innato, las circunstancias externas que nos influyen y que en su variopinta multiplicidad afectan al hombre bien profunda, bien efímeramente, se ocupan, de hecho, de conformar el modo en el que él, como hombre, se muestra tanto en el aspecto moral como en el espiritual" (NiETzsche, F. 20 i I, "Esbozos autobiográficos (1858-1869)", op. cit., 10[8], 124).

${ }^{5}$ Nietzsche, F. 20 i i, "Esbozos autobiográficos (1858-1869)", op. cit., 85. 
Pero quiero que se me vea aquí retratado en mi forma más sencilla, natural y ordinaria, sin artificio ni contención: porque es a mí a quien pinto". ${ }^{6}$

Del Goethe autobiógrafo Nietzsche se acordará cuando se disponga a dotar a sus escritos pasados de nuevos prefacios, con el intento de proporcionar a sus lectores un cuadro completo y coherente de sí mismo; ${ }^{7}$ o quizás cuando, en una pausa de jocosa seriedad, piense en Ecce homo: por lo demás, sugiere Goethe, para los escritores "debería resultar muy entretenida y revitalizadora la tarea de tratar nuevamente lo ya creado y hacer de ello un último tema que contribuirá nuevamente a la formación de quienes antańo se formaron con el artista y en su obra". ${ }^{8}$

Pero propongo la hipótesis de que en el empujar a Nietzsche por el camino de la emulación también pueda haber tenido algo que ver la Lebensgeschichte de Johann Heinrich Jung-Stilling, apreciada por el propio Goethe hasta el punto de promover su publicación: la tercera edición de esta obra, conservada aún en la biblioteca de Nietzsche, ${ }^{9}$ es de 1858, el mismo año en que el futuro filósofo se enfrenta a sus primeras tentativas autobiográficas.

La publicación de la Lebensgeschichte, en 1777, representa una etapa significativa en el panorama de la literatura autobiográfica alemana: ${ }^{10}$ completamente en el seno de la tradición pietista, su autor no renuncia sin embargo al autoanálisis y la búsqueda de una identidad propia, si bien guiado por la sabia brújula de la Providencia. ${ }^{11} \mathrm{Si}$ bien para los pietistas, en efecto, la autobiografía coincide con el relato del propio itinerario hacia Dios, Stilling, sin embargo, no se ahorra las propensiones poéticas y descriptivas, las narraciones de acontecimientos domésticos, los retratos de los amigos, casi asomándose un conflicto,

\footnotetext{
${ }^{6}$ De Montaigne, M. 2005, Ensayos, vol. I, traducción, introducción y notas de Marie-José Lemarchand, Madrid: Gredos, 47.

7 "Tenemos reunidas ya, mi querido amigo, las doce partes de su obra poética y, al leerlas, encontramos algunas cosas conocidas y otras que no lo son, mientras que algunas olvidadas recobran frescura a través de esta recopilación. Resulta inevitable contemplar como un todo estos doce volúmenes que en un único formato aparecen ante nosotros, un todo que suscita el deseo de deducir a partir de él una imagen del autor y de su talento" (Goethe, J. W. 20 ıo, op. cit., 19).

${ }^{8}$ Ibíd., 4.

${ }^{9}$ En BN: Jung (Stilling), J. H. I 857, Lebensgeschichte, oder dessen Jugend, Jünglingsjahre, Wanderschaft, Lehrjahre, bäusliches Leben und Alter. Eine wahrhafte Geschichte, 3te Auflage, Stuttgart.

${ }^{10}$ Cfr. Morenghi, E. 2004, "La Lebensgeschichte di Johann Heinrich Jung-Stilling tra autobiografia e romanzo", Torre di Babele. Rivista di letteratura e linguistica, 2: 109.

${ }^{11}$ Así el joven Nietzsche: "Los años huyen en fila ante mi mirada igual que en un confuso sueño. Por eso me resulta imposible precisar fechas para los primeros diez años de mi vida. No obstante, algunas cosas se presentan con claridad y vivacidad a mi espíritu, y quiero ordenarlas en un cuadro uniendo luces y sombras" (Nietzsche, F. 20 I I, "Esbozos autobiográficos (18581869)", op. cit., 4[77], 67).
} 
podríamos decir, entre "la Ilustración que da libertad y un Romanticismo que restituye su valor al pasado, a las esperanzas de redención, a la consistencia estructuradora de la nostalgia". ${ }^{12}$ Nietzsche, tan exigente en cuestión de gusto, salvará también este "tesoro de la poesía alemana":

Si se prescinde de los escritos de Goethe, y particularmente de las conversaciones de Goethe con Eckermann, el mejor libro alemán que exista: ¿qué queda propiamente de la literatura alemana en prosa, que merezca ser leído una y otra vez? Los aforismos de Lichtenberg, el primer libro de la biografía de JungStilling, el Verano tardio de Adalbert Stifter, la Gente de Seldwyla de Gottfried Keller, - y por el momento eso es todo. ${ }^{13}$

El relato de la conversión y de la experiencia religiosa en Stilling se convierte en excavación interior, viaje por los senderos de la intimidad individual; según Ladislao Mittner y Claudio Magris, es del pietismo y de su secularización de donde nacerán la literatura alemana moderna y, aún más, el viaje al descubrimiento del frágil y sensible sujeto moderno. Nos gusta pensar que el camino de Nietzsche en busca de la propia identidad empieza aquí: de la admiración por las vidas ejemplares, focalización de individualidades singulares de la fuerza particular ${ }^{14}$ (“QQué extraordinaria falta de libros en nuestra época que respiren una fuerza heroica! - ¡Ni siquiera se lee a Plutarco!”"15), a las tentativas de Selbstbildung de sabor goethiano, ${ }^{16}$ para finalmente recalar en una nueva concepción de sujeto y, por consiguiente, de yo-narrante. Por decirlo con Magris, "con esta narrativa pietista, que en el libro de Jung Stilling encuentra su culminación, comienza una parábola que llegará hasta los héroes contemporáneos de

${ }^{12}$ Cfr. Ascarelli, R. 200 i, "Autobiografia e invenzione di sé", Aperture, 11-12: 91.

${ }^{13}$ WS 109, 406. Nietzsche proclama también en otro lugar su gran admiración por Der grüne Heinrich de Gottfried Keller, que a menudo se acerca al género de la autobiografía.

${ }^{14}$ En sus primeras cartas, la petición a amigos y parientes de libros biográficos: Platen, von Humbold, Hölderlin.

${ }^{15}$ FP I, 19[33] (verano de 1872-comienzo de 1873). Cfr. también: 29[230] (verano-otońo de 1873); 30[31] (otoño de 1873-invierno de 1873-74) y notas relativas (ibíd., 517 y 529).

16 "En la investigación goethiana encontramos, sin embargo, una orientación antitética respecto a la intención de la escritura nietzscheana [...] El título Poesía y verdad remite, de hecho, a la idea de que el análisis autobiográfico no puede sino ser tipológico, esto es, fundado en la capacidad de la poesía para captar los rasgos característicos y típicos de las relaciones homeostáticas entre el tiempo y el individuo: dimensión orgánica e interdependiente del Lebenslauf, que en Nietzsche se pierde completamente" (GALlo, F. 2007, "Ecce homo: scrittura di sé, monumentalizzazione e narrazione dell'identità. Autobiografia e destinazione postuma della filosofia in Nietzsche tra Goethe, il decadentismo e Leopardi”, en Autobiografia, autobiografie, ricostruzione di sé, Mezzanzanica M. (ed.), Milán: FrancoAngeli, 52). 
la negación y de la ausencia, los grandes personajes que descubrirán, indagándose a sí mismos, no querer y no poder tener ninguna biografía". ${ }^{17}$ Quién sabe si no será justamente esta la parábola nietzscheana misma.

2 .

Así pues: escribe Historia el individuo experto y superior. Quien no ha tenido experiencia de algunas cosas en forma más grande y elevada que todos los demás tampoco sabrá extraer nada grande y elevado de la interpretación del pasado. La sentencia del pasado es siempre un oráculo: únicamente lo entenderéis como arquitectos del futuro y como sabedores del presente. [...] En cambio, si os compenetráis con la Historia de grandes hombres, extraeréis de ella un supremo mandamiento de alcanzar la madurez y de huir del yugo paralizador de la educación actual, a la que le conviene no dejaros alcanzar la madurez, con el fin de dominaros y explotaros a vosotros, que sois inmaduros. Y cuando pedís biografías, que no sean de esas que dicen: "Señor fulano de tal y su época", sino biografías en cuya portada tendría que estar inscrita esta leyenda: "Uno que luchó contra su época”. Saciad vuestras almas leyendo a Plutarco y, creyendo en sus héroes, atreveos a creer en vosotros mismos. Con un centenar de tales seres humanos educados de forma no-moderna, esto es, convertidos en maduros y habituados a lo heroico, ha de reducirse ahora a eterno silencio toda la ruidosa pseudoformación de esta época. ${ }^{18}$

Este pasaje de la segunda Intempestiva, dedicada a la historia, nos pone, entre otras cosas, frente al problema de la relación entre el individuo y las propias condiciones de existencia. A aproximadamente una década de sus tentativas juveniles de considerarse fruto coherente de las circunstancias, Nietzsche parece oponer ahora a la mirada reconstructiva del oráculo délfico ("conócete a ti mismo"), una imagen de sí llamada a constituirse en el futuro. Nietzsche no está dispuesto a dejar pasivamente a la historia la tarea de decidir la suerte del individuo, ni de reconocer a la vida de este un valor meramente paradigmático, dentro del panorama de la evolución cultural y literaria del propio tiempo. La reflexión sobre la historia, la neta oposición al justificacionismo hegeliano y

${ }^{17}$ Cfr. Magris, C. I993, "L'anima romantica d'un tedesco di provincia”, Corriere della sera, 19 diciembre.

${ }^{18}$ HL 6, 724-5. 
a su teorización de un camino necesario y providente, caracteriza también la dimensión biográfica y autobiográfica. ${ }^{19}$

Frente a un individuo absorbido y comprendido de nuevo por el flujo paralizante de la historia, Nietzsche prefiere un individuo capaz de cargar la historia — también la propia historia- de significado, de asimilar subjetivamente todas sus potencialidades. Será Emerson quien confirmará este punto de vista, con palabras que Nietzsche no podrá dejar de transcribir en sus cuadernos:

El instinto dormido del alma se deja ver en el provecho que sabemos extraer de la historia: solo hay biografía. Cada hombre debe saber cuál es su tarea. Tiene que desaparecer ese absurdo allí y entonces sin plan ni elaboración y que los sustituya el aquí y ahora. ${ }^{20}$

Si la historia adquiere sentido solo en una dimensión proyectiva y personal —que tomará muy pronto connotaciones antiheroicas y antiidealistas-,${ }^{21}$ la noción de tarea será particularmente pregnante en la construcción nietzscheana de la propia biografía. En los últimos años de su vida consciente, Nietzsche sentirá como mandato fatal aquella Transvaloración de todos los valores destinada a cambiar para siempre la suerte de la humanidad; ${ }^{22}$ en el

19 "Hegel: 'El interés de una biografía parece contraponerse directamente a un fin general, pero esa misma tiene como trasfondo el mundo histórico, en el cual está implicado el individuo.' De ahí, por lo tanto, el título justificativo de 'Demóstenes y su tiempo', etc. Si hay diez biografías de la misma época, se tiene diez veces la misma cosa: ¡la manía de escribir libros! Sobre el 'espíritu de la época de Ambrosio o incuso — por decirlo con Lichter - algo sobre la particular individualidad de Ambrosio, en cuanto que está implicada en el trasfondo de aquella época”". [FP I, 29[74], 480 (verano-otońo de 1873)].

${ }^{20}$ FP II, 17[5], 895 (comienzo de 1882; extractos de los Ensayos de Emerson). Cfr. ZavatTA, B. 2006, La sfida del carattere. Nietzsche lettore di Emerson, Roma: Editori Riuniti, particularmente para este tema, 107 ss. La presencia de Emerson, como ha mostrado Zavatta, resulta imprescindible para el camino de Nietzsche en dirección a una nueva individualidad y a una nueva "forma", a partir de la común lección goethiana. Pero dentro de la comparación entre los dos autores se delinearía un doble movimiento, el primero en dirección a la construcción de la individualidad, al fortalecimiento del ego; el segundo en dirección a una superación en el cósmico sentir del amor fati. "Si en Emerson esta desenfrenada ampliación del sujeto conduce a accesos de misticismo en los que el individuo se hace una sola cosa con la superalma que conforman la naturaleza y la historia, en Nietzsche esto provoca una desintegración de la personalidad, en su caso no solo teorizada sino finalmente también realizada" (cfr. ibíd., 185-6).

${ }^{21}$ Véase a propósito Campioni, G. 2008, Nietzsche. La morale dell'eroe, Pisa: ETS, en particular el capítulo 1.

22 " ¡Si pudiera darse una idea de mi sentimiento de soledad! Ni entre los vivientes ni entre los muertos tengo a nadie con quien me sienta afín. Esto es de un horror indescriptible; y sólo el ejercicio de soportar ese sentimiento y un desarrollo gradual del mismo desde la nińez me hace comprensible que no haya sucumbido por su causa. - Por lo demás, la tarea por la cual vivo está ante mí con claridad — como un factum de indescriptible tristeza, pero transfigurado 
origen de esta fatalidad, unas "habilidades prácticas y teóricas para interpretar y ordenar los acontecimientos", a la luz de aquello que cada uno de nosotros tiene el deber de hacer de sí mismo. ${ }^{23}$ Recorriendo en 1887 las páginas del ensayo sobre La psicología de los grandes hombres de Henri Joly, Nietzsche, que no abandonará nunca la reflexión sobre cómo puede distinguirse y en qué se caracteriza el individuo excepcional, marca vistosamente un pasaje en el que podría haberse reconocido:

La potencia intelectual, en la medida en que tiene conciencia de sí misma, se dirige hacia un objeto siempre más grande. ¿Qué ocurre entonces? Que las facultades se unen, que los esfuerzos se coordinan, que la intensidad de la pasión misma se pone al servicio de un gran designio. Pero ponerse al servicio de una idea es plegarse a sus exigencias, es admitir una regla, es introducir en los propios movimientos un orden que no se deja desarrollar sino alli donde debe, pero con una energía sostenida y dirigida por el presentimiento del éxito. ${ }^{24}$

Nietzsche añade una larga línea al margen, y escribe a pie de página "NB Das Ziel _—”, el resto, desgraciadamente, está cortado por la mano de un descuidado encuadernador.

Das Ziel, la tarea, el fin, que ilumina el horizonte: un horizonte, sin embargo, que apenas se entrevé, si bien es cierto que la admonición délfica no hace más por nosotros. ${ }^{25}$ Conocerse, describirse, narrarse, se hace imposible

por la conciencia de que hay en ello algo grande, si jamás algo grande ha habitado la tarea de un mortal." (a F. Overbeck, el 5 de agosto de 1886, Correspondencia, vol. V (enero de 1885-octubre de 1887), traducción, introducción, notas y apéndices de Juan Luis Vermal, Madrid: Trotta, 20 I 2, 198); "Yo también estoy en plena actividad; y los perfiles de la, sin duda alguna, colosal tarea que ahora se halla ante mí resaltan en la niebla cada vez con mayor claridad. Ha habido horas sombrías, ha habido entre tanto días y noches enteros en que no sabía ya cómo vivir y en los que se apoderó de mí una negra desesperación, como aún no la había sufrido hasta ahora. No obstante, sé que no puedo escabullirme ni yendo hacia atrás, ni hacia la derecha, ni hacia la izquierda: no tengo elección" (a F. Overbeck, el 3 de febrero de 1888, Correspondencia, vol. VI (octubre de 1887-enero de 1889), traducción, introducción, notas y apéndices de Joan B. Llinares, Madrid: Trotta, 20 I 2, 107).

${ }^{23}$ Cfr. FW 277: 830. Para estos temas me permito remitir a Fornari, M. C. 2013 , "E così mi racconterò la mia vita'. Nietzsche dalle ultime lettere (1885-1889)", en Goethe, Schopenhauer, Nietzsche. Saggi in memoria di Sandro Barbera, Campioni, G., Pica Ciamarra, L., Segala, M. (eds.), Pisa: ETS, 289-301.

${ }^{24} \mathrm{BN}$ : Joly, H. I 883, Psychologie des grands hommes, París: Hachette, 86. Las cursivas corresponden a los subrayados de Nietzsche.

25 "Nosotros los que conocemos somos desconocidos para nosotros mismos, nosotros mismos somos desconocidos para nosotros mismos: esto tiene un buen fundamento. No nos hemos buscado nunca, —¿cómo iba a suceder que un día nos encontrásemos?" (GM, "Prefacio", 1, 21). 
en una hermenéutica como la nietzscheana, en la que el sujeto tradicional se ha disuelto completamente (aquí es inviable recorrer y resumir la innumerable bibliografía, a partir de Foucault, dedicada a la crisis de la subjetividad y a nuevas, posibles, experiencias del sí). Sin contar la mendacidad moralista, la mentira deshonesta que afecta al hombre moderno ("Esos 'hombres buenos' - todos ellos están ahora moralizados de los pies a la cabeza, y, en lo que respecta a la honestidad, han quedado malogrados y estropeados para toda la eternidad: ¡quién de ellos soportaría aún una verdad 'sobre el hombre!...' O, para concretar más la pregunta: ¿quién de ellos soportaría una biografía verdadera... [?]"26), es razón suficiente para poner en guardia frente a si mismo al más inteligente de los psicólogos. ${ }^{27}$

¿Qué espacio de posibilidad le queda, por tanto, a aquel que quiere narrase a sí mismo? Nietzsche no renuncia a ello completamente:

El día de mi cumpleaños he vuelto a comenzar algo que parece que sale bien y ya está notablemente adelantado. Se llama ECCE HOMO. O Cómo se llega a ser lo que se es. Trata, con una gran audacia, de mí y de mis escritos [...] Por lo demás, hablo de mí mismo con toda la "astucia" psicológica y toda la serenidad posibles, - en modo alguno quisiera presentarme ante los seres humanos como profeta, como monstruo o como aberración moral. Hasta en este sentido este libro podría ser positivo: impediría acaso que se me confunda con mi antitesis_- ${ }^{28}$

Un libro "de absoluta importancia", que "ofrece alguna pista psicológica e incluso biográfica sobre mí y mi literatura: de golpe se me podrá ver". ${ }^{29}$

Pero el yo-narrante de Ecce homo cuenta en realidad la historia de un descubrimiento, que tiene lugar en el acto mismo de su realizarse. Recorriendo retrospectivamente la experiencia de sus escritos pasados, con el objetivo de

${ }^{26}$ GM III, 19, 177.

${ }^{27}$ Cfr. GM III, 20. Pero ya en FW (91, 782-3): “Precaución. - Alfieri, como se sabe, mintió muchísimo al contar a sus sorprendidos contemporáneos la historia de su vida. Mintió ejerciendo ese despotismo contra sí mismo que demostró, por ejemplo, en el modo en que creó su propio lenguaje y se tiranizó para convertirse en poeta: - había encontrado finalmente una estricta forma de elevación en la que forzó a entrar a su vida y su memoria: tiene que haber habido mucho tormento en ello. - Tampoco le daría ningún crédito a una biografía de Platón escrita por él mismo: tan poco como a la de Rousseau, o a la vita nuova de Dante". No hay que olvidar, sin embargo, que "Alfieri tenía el sentido del gran estilo" (FP 9[183] otońo de 1887, 294). En BN: Alfieri, V. I 8 I 2, Denkwürdigkeiten aus dem Leben Vittorio Alfieri's. Von ihm selbst geschrieben, Cölln; Rousseau, J. J. I 870, Bekenntnisse. Neun Theile in zwei Bänden, Leipzig; Alighieri, D. I84I, Das neue Leben, Leipzig.

${ }^{28}$ A H. Köselitz, 30 de octubre de 1888: Correspondencia, vol. VI, 281-2.

${ }^{29}$ A F. Overbeck, 13 de noviembre de 1888: Correspondencia, vol. VI, 288. 
hacerse comprensible y eficaz para una acción sobre el presente, ${ }^{30}$ Nietzsche traza una evolución personal de la que solamente a posteriori puede llegar a ser él mismo consciente. Recorrer las propias obras, descubrir su fatal, íntima coherencia, constituye para Nietzsche, quizá, una tan inesperada como feliz vía de escape: es en sus escritos donde habita su "ego ipsissimus, e incluso, si se me permite una expresión más orgullosa, ego ipsissimum", ${ }^{31}$ donde el neutro, en mi opinión, subraya la superación de la dimensión egóica tradicional. ${ }^{32}$

Nietzsche puede, así, cumplir con otra tarea que desde siempre le ha interesado mucho: demostrar, encarnar el cortocircuito entre arte y vida, entre estilo y carácter, presupuesto imprescindible de toda producción artística.

"Dar estilo" al propio carácter — ¡un arte grande y poco frecuente! Lo ejerce aquel que abarca con la mirada todas las fuerzas y debilidades que ofrece su naturaleza y las integra luego en un plan artístico hasta que cada una de ellas aparezca como arte y razón y hasta la debilidad fascine a la vista... ${ }^{33}$

parece ya una premonición de Ecce homo que es, en el fondo, "también la ostensión de un cuerpo - que se realiza esencialmente como corpus de obrasque supera la enfermedad y la decadencia gracias a una forma y a un estilo superiores", ${ }^{34}$ un estilo que caracteriza, a la vez, producción y vida. ${ }^{35}$

3. Este modelo de subjetividad, la exigencia de construir una identidad que no sea comunicable inmediatamente, sino solo mediada por una afinidad experiencial, ${ }^{36}$ parece responder bien a la incapacidad de las perspectivas

30 "Como preveo que dentro de poco tendré que dirigirme a la humanidad presentándole la más grave exigencia que jamás se le ha hecho, me parece indispensable decir quién soy yo" (EH, "Prólogo", 1, 17).

${ }^{31}$ MA II, "Prefacio", 1 (1887), 275.

${ }^{32}$ Cfr. Lupo, L. 2013, "Appena prima del buio", en Goethe, Schopenhuer, Nietzsche. Saggi in memoria di Sandro Barbera, op. cit., 463-72.

${ }^{33} \mathrm{FW} 290,834$.

${ }^{34}$ Campioni, G. 2008, "Introduzione" a Nietzsche, F., Lettere da Torino, Milán: Adelphi, 20.

${ }^{35}$ Schusterman define esta "ética de la estilización de sî" como "estética pragmática", recorriendo la idea deweyana de que el objeto de la estética no es la fruición intelectual de la obra de arte, sino la vida entera. El autor la vuelve a encontrar en Emerson, Nietzsche y Wittgenstein: cfr. Shusterman, R. 1997, "Style et styles de vie: originalité, authenticité et dédoublement du moi”, Littérature, 105: 102-9.

36 "Para entenderse no basta emplear las mismas palabras: hay que emplear las mismas palabras también para el mismo género de vivencias internas - y se han de tener éstas EN COMÚN. [...] Esto está dicho para explicar por qué es difícil entender escritos como los míos: las vivencias 
teóricas tradicionales de dar cuenta de la complejidad psicológica y ontológica de un (im)probable yo. ${ }^{37}$ Algo muy diferente a una adquisición, simple expresión de algo que se posee, el yo se convierte en el producto de una construcción móvil, una unidad de tensión dinámica en devenir: esta idea, como decía, se encuentra reincorporada en la exhortación nietzscheana a llegar a ser lo que se es. ${ }^{38}$ Junto a la que Schusterman define como "estrategia bio-ontológica" (la originalidad de cada individuo es garantizada ontológicamente por la singularidad de las combinaciones no reiterables de los factores que lo producen), construir el yo con el fin de incluir en él no solo "lo que ya se es, sino, de manera aún más decisiva, lo que se puede llegar a ser", entendido como camino de "auto-estilización", sería la segunda estrategia puesta en juego por Nietzsche en su defensa del estilo como expresión de sí. ${ }^{39}$

A pesar del persuasivo carácter enigmático de su texto autobiográfico, en el fondo, Nietzsche juega con las cartas descubiertas. Desde el primer capítulo de Ecce homo, "Por qué soy yo tan sabio", imputa a la fatalidad de su existencia su naturaleza ambigua ("como mi padre ya he muerto, y como mi madre vivo todavía y voy haciéndome viejo"; "Descontando, pues, que soy un décadent, soy también su antítesis" ${ }^{* 0}$ ) pero también a una construcción consciente, que se revela, sin embargo, síntoma y consecuencia a la vez de su estado. Lo

íntimas, las estimaciones de valor y las necesidades son en mí diferentes." (FP III, 34[86] 1885, 733-4).

37 "La recuperación de la naturaleza y de la autenticidad carnal y emotiva de la condición humana [...] se desvanece frente a la constatación de la inaccesibilidad, para la mayor parte de los individuos, de la propia naturaleza y de la propia corporeidad como espacio plausible de realización y expresión del propio deseo [...] En este marco la exigencia autobiográfica adquiere ante todo el sentido de una necesidad de distinción y de construcción de una plausible identidad que sea desde un principio autónoma, no fungible, no compartible si no es solo electivamente" (GALLO, F. 2007, op. cit., 48). Gallo, que cuenta a Nietzsche entre los pocos, grandes e integrales experimentadores de la décadence, considera esta última el campo de innovación radical en el estilo de la existencia individual, que se elabora en las formas de la originalidad subjetiva, de la extravagancia, de la singularidad absoluta. "En este marco la inspectio sui y el proceso autobiográfico se convierten, según la especificidad con la que serían declinados por cada autor, en lugares de polarización y de relación de nuevas estructuraciones del pensamiento y de la belleza, del valor y de la experiencia" (Ibíd., 49).

38 "Un precepto paradójico que remite a un dinamismo interno, a una forma de autoconstrucción caracterizada por el movimiento, ocupa así el lugar del imperativo finalista. El no saber adónde se está yendo, en otras palabras, la ausencia de una meta predeterminada del movimiento y la 'desviación' son seńaladas por Nietzsche como precondiciones para el 'llegar a ser lo que se es”" (Lupo, L. 20 12, Filosofia della Serendipity, Nápoles: Guida, 22-3). Cfr. EH, "Por qué soy yo tan inteligente", 8.

${ }^{39}$ Esto implica una "trasformación artificial de sî", que, sin embargo, debe constituirse sobre un yo original y auténtico. Cfr. Shusterman, R. 1997, op. cit., 105-6.

${ }^{40} \mathrm{EH}$, "Por qué soy yo tan sabio", 1 y 2, 25 y 27. [N. de los T.] 
que se es, a condición de que se lo sepa escuchar, guía y dirime las elecciones vitales - Nietzsche está orgulloso de haber comprendido el significado real del "cornarismo"-,${ }^{41}$ elabora estrategias de agudización y potenciación de los propios recursos; pero al mismo tiempo requiere capacidades activas de selección, de dominio, de elección, en vista de lo que el instinto tiene reservado para nosotros: ${ }^{42}$

Entretanto sigue creciendo en la profundidad la "idea" organizadora, la idea llamada a dominar, - comienza a dar órdenes, nos saca lentamente, con su guía, de los caminos secundarios y equivocados, prepara cualidades y capacidades singulares que alguna vez demostrarán ser indispensables como medios para el todo, - ella va configurando una tras otra todas las facultades subalternas antes de dejar oír algo de la tarea dominante, de la "meta", la "finalidad", el "sentido". — Contemplada en este aspecto, mi vida es sencillamente prodigiosa. ${ }^{43}$

Pero "una cosa soy yo, otra cosa son mis escritos", ${ }^{44}$ puntualiza Nietzsche. ¿Debemos creerle? No del todo, si es cierta la definición que él mismo da del estilo como de un "comunicar un estado, una tensión interna de pathos, por

${ }^{41}$ Cfr. GD, "Los cuatro grandes errores", 1.

${ }^{42}$ Esta conmixtión de hado y construcción consciente de la propia forma de vida puede parecer contradictoria en cuanto que el primero haría coherentemente vana la segunda (cfr., por ejemplo, WS 61). En realidad, reconocer la propia, fatal configuración es lo que guiará proficuamente nuestro destino ("El fatum es un pensamiento sublime para aquel que comprende que él forma parte del mismo", FP III, 26[442], 1884, 613): no dejarse perder frente a tal conciencia, sino, más bien, trabajar para favorecer su realización, es según mi opinión el signo de una cultura superior. La maravillosa armonía que nace de los sonidos de nuestro instrumento, "una armonía que suena demasiado bien como para que osemos atribuírnosla a nosotros mismos" (FW 277, 830), es el encuentro de la casualidad con la capacidad de desplegar hasta el fondo la unicidad de la propia condición, en una feliz coincidencia de voluntad y destino. En este sentido, es esclarecedor lo que Nietzsche escribe a Paul Deussen, con ocasión de su cumpleańos: "Tengo un concepto tan elevado de tu activa e intrépida existencia que tiene poco sentido expresar deseos especiales. A aquel que ha de poner una voluntad propia en las cosas, estas no lo dominarán; últimamente las casualidades se coordinan incluso con nuestras necesidades más propias. A menudo me asombro de lo poco que puede la máxima desgracia del destino sobre una voluntad. $\mathrm{O}$ al contrario: me digo lo mucho que la voluntad misma ha de ser destino de manera que triunfe una y otra vez incluso contra el destino, vंjè VI, 91). Véase también el interesante escrito juvenil, compuesto bajo la influencia de Emerson, "Fatum e historia" (1862) en Nietzsche, F. Obras Completas. Volumen I: Escritos de juventud, op. cit., 201-9. Agradezco a Pietro Gori y a Paolo Stellino por haberme invitado a reflexionar sobre este punto.

${ }^{43} \mathrm{EH}$, "Por qué soy yo tan inteligente", 9, 57-8.

${ }^{44} \mathrm{EH}$, "Por qué escribo yo libros tan buenos", 1, 63. [N. de los T.] 
medio de signos", en una exacta correspondencia entre ritmo y gesto. ${ }^{45}$ Por lo demás, si el gran estilo expresa "un inmenso arriba y abajo de pasión sublime, de pasión sobrehumana", ${ }^{46}$ Nietzsche admite haberlo descubierto, experimentado él mismo: sus escritos, Ecce homo incluido, y quizá este más que cualquier otro, solo pueden ser, por tanto, sintomas y, a la vez, resultado, de lo que él mismo es.

Su percibirse como "discípulo del filósofo Dioniso", en plenitud de energía, caracteriza personalidad y producción. ${ }^{47}$ No sorprende entonces que él "se ponga ahora en escena llevando al extremo el arte del gesto, haciendo de su misma escritura un 'gesto', y definiéndose muchas veces como bufón de la eternidad y del destino" ${ }^{48}$ La suya será, por tanto, una lengua "esencialmente disimuladora, irónica y funcional a un larvatus prodeo", ${ }^{49}$ llamada a comunicar estados excepcionales y profundas fuerzas emotivas; la forma, la del pamphlet, la única posible de escritura del sí en una época de decadencia y de fragmentación. La escritura autobiográfica de Nietzsche, en síntesis, no podrá ser una reconstrucción meramente narrativa del determinarse de una identidad personal, sino, más bien, una "radical fabulación", sustitutiva del tradicional lenguaje de la interioridad y de la conciencia de sí, y que comparte más cosas con la esfera de la praxis. ${ }^{50}$

${ }^{45} \mathrm{EH}$, "Por qué escribo yo libros tan buenos", 4. Cfr. también la carta a J.V. Widmann, del 4 de febrero de 1888: "La dificultad de mis escritos radica en que en ellos hay una preponderancia de estados del alma infrecuentes y nuevos sobre los estados anímicos normales. No lo alabo; pero es así. Yo busco signos para esos estados todavía no percibidos y a menudo apenas perceptibles; me parece que en ello tengo mi inventiva. [...] El propósito de un escrito ¿̨no ha de crear siempre y en primer lugar la ley de su estilo? Yo exijo que, si se altera ese propósito, se altere también inexorablemente todo el sistema de procedimientos estilísticos" (Correspondencia, vol. VI, 109-10).

${ }^{46} \mathrm{EH}$, "Por qué escribo yo libros tan buenos", 4, 70. [N. de los T.]

47 "Querido y apreciado amigo: Escribirme una carta así ha sido el fruto de un momento muy bueno. Pues, casi sin la voluntad para hacerlo, pero de conformidad con una necesidad inexorable, me encuentro justamente en pleno saldo de cuentas con personas y cosas en relación conmigo y dando carpetazo a todo lo que he sido 'hasta ahora'. Casi todo lo que hago en la actualidad es un borrón y cuenta nueva. La vehemencia de las oscilaciones internas ha sido horrible durante los últimos años; ahora, cuando he de pasar a una forma nueva y más elevada, necesito ante todo un nuevo extrañamiento, una despersonalización todavía más elevada” (a C. Fuchs, 14 de diciembre de 1887: Correspondencia, vol. VI, 516).

${ }^{48}$ Campioni, G. 2008, op. cit., 22.

${ }^{49}$ Cfr. Gallo, F. 2007, op. cit., 60.

${ }^{50}$ Cfr. Gallo, F. 2004, Nietzsche e l'emancipazione estetica, Roma: Manifestolibri, 29-30. Gallo sugiere que Nietzsche intenta "un nuevo acercamiento constructivo, orientado hacia una sólida fijación de la subjetividad, pero en el sentido de su declinación pragmático-operativa, de la que sobresale la característica curvatura postmoderna" (Ibíd., 31-2). 
Una autobiografía, por tanto, que si no traiciona el usual pacto autobiográfico, ${ }^{51}$ difícilmente puede, sin embargo, afrontarse con los medios hermenéuticos y especulativos tradicionales. Nietzsche intenta aquí algo que quizá ya está más allá del ámbito del pensamiento representativo: como bien dice Roberto Calasso, él parece haber querido hacer visible el tránsito "desde una teoría radical, pero respetuosa aún con una convención formal, a una práctica de carácter inaudito, que quedará para siempre como su punto más misterioso". ${ }^{52}$

El análisis sobre el sendero de la conciencia se ha llevado tan adelante como para haber dejado intacto solo el universo de los signos: el mundo quiere ser dicho en otra lengua. Nietzsche abandona la filosofía - y el mundo consciente, teatro de la falsificación - con un gesto brusco:

Ahora, el mar de la fuerza, donde ninguno de los gestos epistemológicos, gestas de un sujeto ficticio, se convierte en una ola salvaje en medio de la inmensidad de las otras. ${ }^{53}$

${ }^{51}$ Según la ya clásica definición de Lejeune, P. 1975, 2005², Le pacte autobiographique, París.

${ }^{52}$ Calasso, R. I983, "Monologo fatale", en apéndice a Nietzsche, F., Ecce homo, Milán: Adelphi, 170 .

${ }^{53}$ Ibíd., 179. 